что ключевым документом в любой организации, переходящей на рельсы информационного моделирования, должен быть BIM-стандарт организации [4]. При разработке собственных BIM-стандартов активно используется опыт зарубежных коллег. Рассмотрим состав стандартов Великобритании, как одной из стран - лидеров по внедрению ВIM.

\section{Стандарты Великобритании}

Стандарты Великобритании в области BIM разрабатываются Британским институтом стандартов (BSI). Статусы разработанных документов по информационному моделированию следующие: BS (British standard) - Британский стандарт и PAS (Publicly Available Specification), наиболее близким вариантом которого в РФ является Проект стандарта. Такая интерпретация следует из описания: процесс создания PAS не требует длительного согласования и утверждения в отличие от Британского стандарта. Данный подход позволяет быстро разработать документ, удовлетворяющий нуждам отрасли. В дальнейшем развитие PAS может рассматриваться в качестве Британского стандарта или стать вкладом Великобритании в разработку составной части Европейского или Международного стандарта [3]

Ниже представлен список Британских стандартов и Проектов стандартов по информационному моделированию с переводом названий на русский язык.

- BS 1192:2007+A2:2016. Британский стандарт. Совместное производство архитектурной, инженерной и строительной информации. Свод правил.

- PAS 1192-2:2013. Проект стандарта для управления информацией на этапе капитального строительства с использованием информационного моделирования.

- PAS 1192-3:2014. Проект стандарта для управления информацией на этапе эксплуатации объекта с использованием информационного моделирования.

- BS 1192-4:2014. Британский стандарт. Совместное производство информации. Выполнение требований заказчика к информационному обмену с использованием СОВіе. Свод правил.

- PAS 1192-5:2015. Проект стандарта по информационной безопасности для информационного моделирования, цифровой среды общих данных и умного управления активами.

- BS 8536-1:2015. Британский стандарт. Инструкция для проектирования и строительства. Свод правил для управления объектами (строительная инфраструктура).

Наиболее часто в работах, связанных с информационным моделированием, упоминается стандарт BS 1192:2007. Однако при детальном изучении данного документа вы не найдёте достаточно информации об информационном мо- делировании, термины BIM (Building Information Modelling, информационное моделирование зданий), AIM (Asset Information Model, информационная модель объекта) и РIM (Project Information Model, информационная модель проекта) в совокупности упоминаются в документе всего 5 раз. Это связано с тем, что стандарт BS 1192:2007 посвящён только организации среды общих данных (СОД), преимущественно на базе файлового хранилища. Таким образом, при изучении опыта английских коллег предлагается уделить большее внимание прикладным документам PAS 11922:2013 и PAS 1192-3:2014.

\section{Управление информацией на этапе капитального \\ строительства \\ с использованием \\ информационного \\ моделирования}

Данный общедоступный Проект стандарта определяет требования для достижения 2-го уровня информационного моделирования (BIM). Требования, предъявляемые в рамках данного Проекта стандарта, опираются на существующие нормы и правила совместного производства архитектурной, инженерной и конструкторской информации, определённые в BS 1192:2007. PAS 1192-2 уделяет особое внимание реализации проектов, для которых большинство документов, графических и неграфических данных, известных под общим названием «информационная модель проекта» (PIM), накапливается в результате проектных и строительных работ.

В целевую аудиторию этого Проекта стандарта входят организации и лица, ответственные за закупки, проектирование, строительство, поставки, эксплуатацию и техническое обслуживание зданий и объектов инфраструктуры.

Требования данного Проекта стандарта начинаются с точки оценки (для существующих объектов) или с рассмотрения необходимости объекта (для нового строительства), далее постепенно работа проходит через различные этапы цикла предоставления информации (рис. 1) и завершается выпуском информационной модели построенного объекта (AIM). Результат передаётся заказчику подрядчиком после того, как исполнительная съёмка сверена с PIM [5].

\section{Управление информацией \\ на этапе эксплуатации \\ объекта с использованием \\ информационного \\ моделирования}

PAS 1192-3:2014 тесно связан с PAS 1192-2:2013, в нём имеется множество ссылок на информационное моделирование на этапе капитального строительства. Проект стандарта определяет требования к информационному управлению для достижения 2-го уровня информационного 


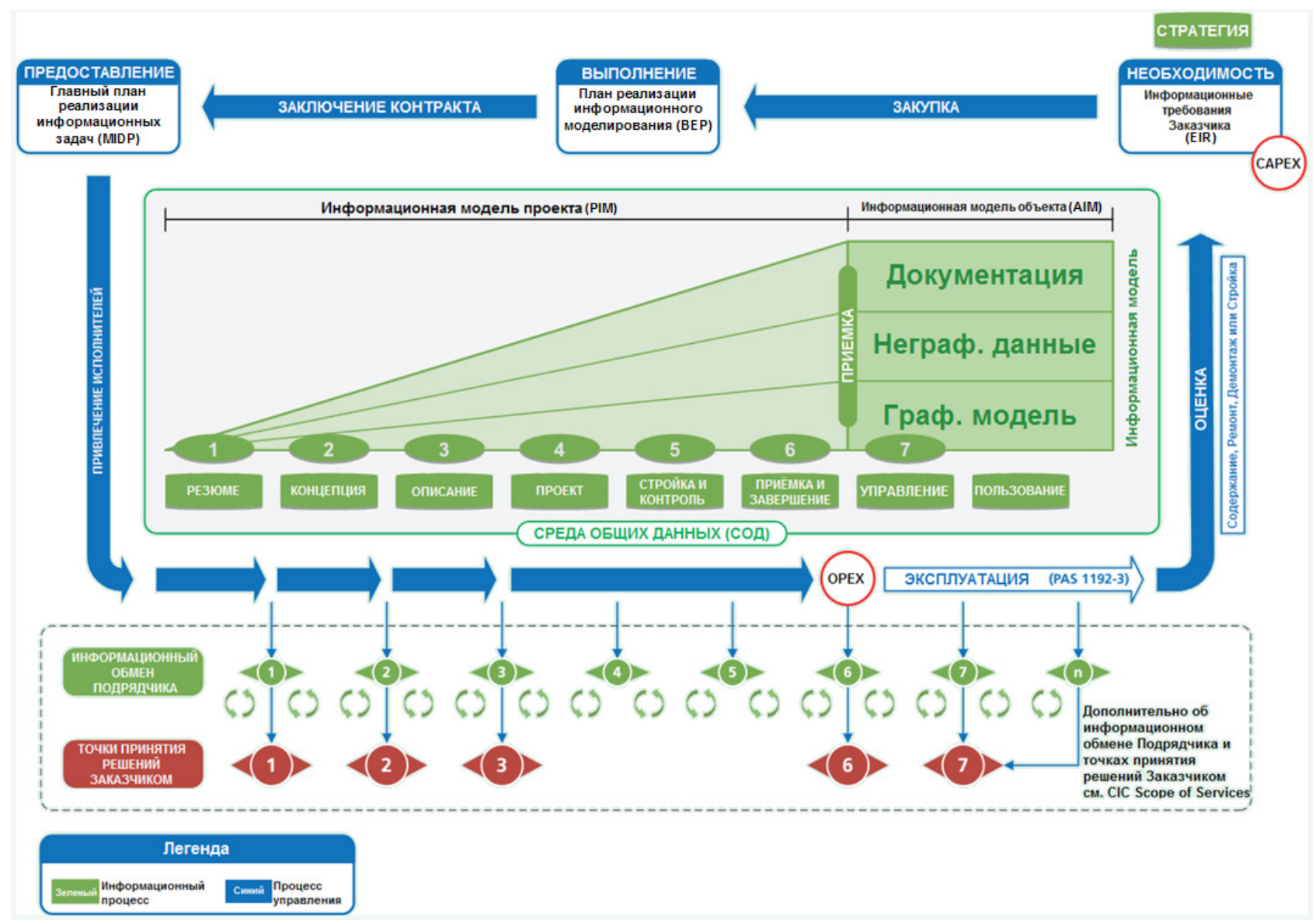

Рис.1. Информационные потоки и цикл управления проектом

моделирования (BIM) по отношению к эксплуатации и техническому обслуживанию объектов (зданий и инфраструктуры).

Охватываются процессы передачи данных:

- создание информационной модели объекта (AIM) для существующего объекта или портфеля объектов;

- обмен информацией об объекте с информационной моделью проекта (PIM);

- запись информации, относящейся к утилизации, выводу из эксплуатации и сносу объекта;

- использование AIM для поддержки организационных требований;

- пересмотр AIM, когда объект изменился;

- использование AIM в качестве ресурса для организации.

Проект стандарта предназначен для использования организациями и физическими лицами, ответственными за эксплуатацию, техническое обслу- живание и стратегическое управление объектами. Он будет полезен для лиц, участвующих в передаче данных из PIM в AIM, используемую организацией, а также для лиц, участвующих в обмене данными на протяжении всего срока службы объекта [6].

Проект стандарта определяет требования к управлению информацией на этапе эксплуатации объектов четырьмя разными способами.

1. Определяются процессы информационного управления, с помощью которых данные и информация, указанные через организационные и информационные требования к объекту, помещаются и извлекаются из AIM и передаются или используются в существующих корпоративных системах там, где это необходимо, для поддержки организационных информационных требований (OIR).

2. Определяется объединённая модель, которая содержит данные и информацию, необходимые для AIM, и объясняется взаимосвязь с РIM, которая определена в PAS 1192-2.

3. Определяется природа и типы данных и информации, которые будут использоваться в информационных обменах в пределах AIM.

4. В Проекте стандарта даётся два детализированных примера процессов для реализации среды общих данных по BS 1192 для различных видов деятельности, связанных с объектами.

Кроме того, показано, как ответственность на высоком уровне может быть распределена между различными заинтересованными сторонами, участвующими в процессах управления информацией. При этом признаётся, что окончательно обязательства определяются в договорах и заказах на выполнение работ.

Распределение обязанностей между частными лицами и организациями зависит от сложности объекта или 


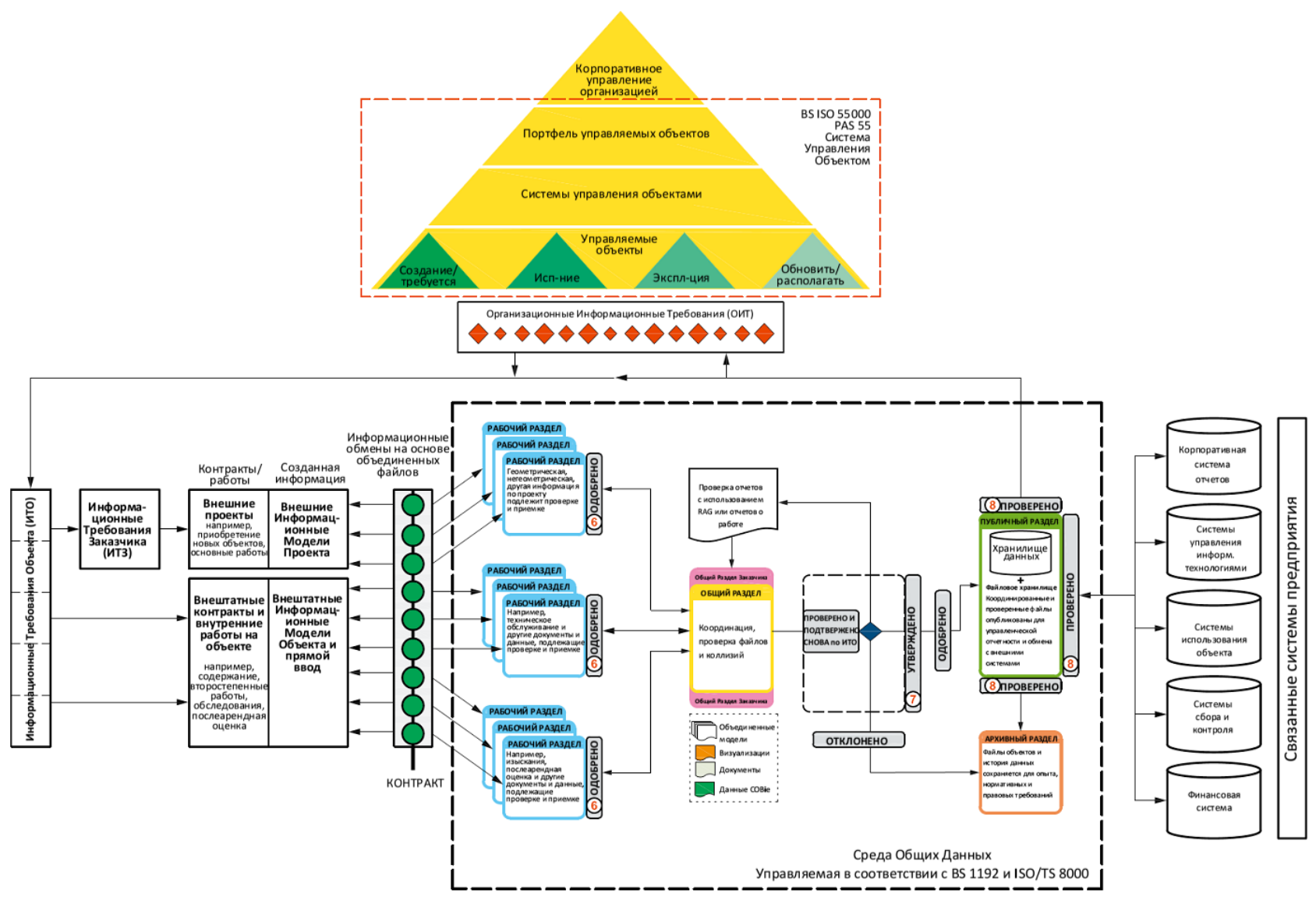

Рис. 2. Обеспечение управления и точности данных и информации на этапе эксплуатации объекта

портфеля и системы управления объектами организации (рис. 2). Целью Проекта стандарта не является создание новых позиций в команде по управлению объектами, однако организации может быть необходим анализ разрывов (GAP-анализ), чтобы оценить существующую квалификацию с учётом требований, определённых в данном Проекте стандарта [6].

\section{Заключение}

Стандарты играют важную роль в обеспечении более широкого применения технологий BIM, процессов и совместной работы, гарантируя, что одинаковые точные данные будут доступны всей цепочке исполнителей. PAS 1192-2:2013 и PAS 1192-3:2014 играют важную роль в принятии цифровых технологий в области управления объектами и организации производства, которые представляют такую большую и важную часть сектора строительной среды. Ознакомиться с тек- стом этих документов на русском языке можно на сайте bimstandart.ru. ㄷ.

\section{Литература:}

1. Гинзбург А.В., Семернин Д.А., Кисель Т.Н. Оценка применения ВIM-технологий в строительстве: Отчёт о работе по договору 32-С/02-16 от 10 февраля 2016 г. М.: Институт экономики, управления и информационных систем в строительстве и недвижимости (ИЭУИС), 2016.51 С.

2. Попов В.А., Бойков В.Н.

Об информационных моделях дорог в технической политике Госкомпании «Автодор» // САПР и ГИС автомобильных дорог. 2014. № 2(3). C. 8-11. DOI: 10.17273/ CADGIS.2014.2.2

3. Баранник С.В. Применимость ВIMтехнологий в дорожной отрасли // САПР и ГИС автомобильных дорог. 2015. № 1(4). C. 24-28. DOI: 10.17273/CADGIS.2015.1.3

4. Российские и международные BIMстандарты // Социальная сеть для делового общения Linkedln. URL: https://www.linkedin. com/pulse/pocсийские-и-международныеbim-стандарты-сергей-баранник (дата обращения: 17.10.2016).
5. PAS 1192-2:2013 (рус.) // ВIM-стандарты Великобритании на русском языке. URL: http://bimstandart.ru (дата обращения: 17.10.2016).

6. PAS 1192-3:2014 (рус.) // ВIM-стандарты Великобритании на русском языке. URL: http://bimstandart.ru (дата обращения: 17.10.2016). 